\title{
Research on Comparative Analysis Toxic Effect of Formalin on MBBS Students of Several Medical College in Bangladesh
}

\author{
Mohammad Nasir Uddin, Curator \\ Department of Anatomy Armed Forces Medical College, Dhaka, Bangladesh \\ Dr. Ismail Miah, Professor \\ Department of Zoology University of Chittagong, Bangladesh \\ Nasrin Akter, \\ Department of Pharmacy Gono Bishwasbidyalay, Bangladesh
}

Doi: 10.19044/esj.2019.v15n12p117 URL:http://dx.doi.org/10.19044/esj.2019.v15n12p117

\section{Abstract}

Formaldehyde is a common indoor pollutant with irritant properties. The evaporation of formaldehyde from cadavers in gross anatomy laboratories can produce high exposure among students and instructors. This study was conducted to assess acute toxic effects of formalin during dissection classes on medical students at the anatomy department in Armed forces medical college, Dhaka (AFMC), Army medical college, Cumilla (AMCC), and Eastern medical college, Cumilla (EMCC) in Bangladesh. A cross sectional approach was adopted to investigate medical students of AFMC $(n=125)$, AMCC $(n=50), \&$ EMCC $(n=75)$.Every medical students filled self administered predesigned questionnaire and submitted research authority. The most frequently reported symptoms by medical students of AFMC, AMCC \& EMCC were unfavorable scent $(84.8 \%, 86 \%, 76 \%)$, Tearing of eyes $(84.8 \%, 90 \%, 72 \%)$, Running nose with prickling sensibility (61.6\%, 82\%, 65.33\%), Neuralgia/migraine (52\%, 86\%, 62.67\%), Inflammation of eyes $(63.2 \%, 84 \%, 66.67 \%)$, Inconvenience inhale \& exhale $(72.8 \%, 86 \%, 66.67 \%)$, Qualm $(80 \%, 84 \%, 60 \%$,$) Extreme tears/$ lacrimation $(87.2 \%, 86 \%, 49.33 \%)$, Sore aphonia/throat $(49.6 \%, 64 \%$, $66.67 \%)$, Scabies $(53.6 \%, 78 \%, 62.67 \%)$, Giddiness $(63.2 \%, 72 \%, 64 \%)$, and Blister(52\%, 70\%, and $65.33 \%$ ) respectively. Moreover in the current research $69.67 \%$, students of AFMC reported wearing laboratory aprons $56.8 \%$, reported wearing hand gloves and 5.6\%, reported wearing eye goggles, where as $92 \%$, of AMCC students reported wearing laboratory aprons/ coat 74\%, student wearing hand gloves and 14\%,students wearing eye goggles. On the other hand $73.33 \%$ of EMCC student reported wearing laboratory aprons $62.67 \%$, students wearing hand gloves as well as only 
$21.33 \%$ students reported wearing eye goggles to protect formalin toxicity. So this research highlighted the irritation action of formalin on medical students during dissection classes in Anatomy department. The harmful effects of formalin can be reduced by some preventive measures like good exhaust ventilation by reducing the concentration of formalin in embalming fluid or using alternative for formalin in the form of phenoxyethanol.

Keywords: Anatomy, Dissection, Dissection Hall, Formaldehyde, Cadaver, Symptom, AFMC, AMCC \& EMCC

\section{Introduction}

The adverse effect of formaldehyde has been discussed very emotionally in public. Anatomist, technicians in histology and embalming laboratories, as well as medical students during their dissection course are all exposed to formaldehyde, which in many situations crosses the threshold for irritation of the eyes and upper respiratory tract. There is no doubt about the acute toxic effects and the occurrence of contact dermatitis caused by formaldehyde.

Most formaldehyde workers are familiar with physical properties and uses of formaldehyde but few are fully aware of its irritant properties. Formaldehyde was discovered in 1856 by the British chemist, August wilheld von Hofman. It is colorless at ordinary temperature and has a irritating pungent odor. It is soluble in water. It is commercially available as formalin containing 37 percent by weight or 40 percent by volume of formaldehyde gas in water. Formalin contains an average of 7 percent methyl alcohol, 37 percent formaldehyde, and the remaining water. Up to 10 percent methyl alcohol is added as a stabilizer, because without this the formaldehyde will precipitate and settle to the bottom as a sediment (Para formaldehyde) and lose strength at ordinary temperature.

Formaldehyde is widely used, e.g., in the chemical, adhesive, paint plastic, construction, textile, paper and cosmetic industries (Bernstein, et al; 1984) Only a small portion of the amounts produced are used in medicine as disinfectant and or fixation of tissue samples or embalming. It has to be remembered that formaldehyde is ubiquitous in our environment. Formaldehyde is produced by cars and released by all fires, such as those in wood-or coal-burning stoves. Cigarette smoke has been reported to contain more than $20 \mathrm{ppm}$ formaldehyde, and about $0.38 \mathrm{mg}$ of formaldehyde is inhaled per pack of cigarettes in main steam smoke (Bernstein, et al; 1984).

Formaldehyde is a noxious gas and classed as an upper respiratory irritant because it has a high solubility in water and is therefore held by the moisture covering the respiratory passages (Gross, et al;1967) The least detectable odour of formaldehyde is reported at $0.05 \mathrm{ppm}$ and the lowest 
concentration causing throat irritation is $0.5 \mathrm{ppm}$ (Stern,(1968) The first symptoms noticed on exposure to small concentration of formaldehyde vapor are unfavorable scent ,burning of the eyes, lacrimation, and general irritation of the upper respiratory passages (Walker, 1964) Fortunately, these symptoms allow formaldehyde to act as its own warning agent as do certain other gases, such as ammonia. Stronger concentrations produces coughing, constriction in the chest, a sense of pressure in the head, palpitation of the heart, and in some cases, a condition which may appear similar to alcoholic intoxication (Walker, 1964) Eye irritation from formaldehyde, a major item of interest currently in air pollution, has been reported to occur in some sensitive individuals at levels which are regarded as "safe" under present recommendations. Morrill (1961) states that the threshold of irritant action to be 0.9 to $1.6 \mathrm{ppm}$ while Bourne and Seferman (1959) have established it at 0.13 to $0.45 \mathrm{ppm}$. Eye irritation panels have tended to confirm the above finding and threshold levels have been recorded by some panel member to be below $0.2 \mathrm{ppm}$.

\section{Aims and Objective}

The main aims of this study are to investigate comparative analysis of acute toxic effects on formalin exposed students in different medical college. Keeping the above views in mind the present work was done setting the following objection:

- To quantify the acute effects of formalin on medical students.

- To recommended appropriate strategies and preventive measure to reduce its toxicity.

\section{Material and Method \\ Site selection}

The present study was a cross sectional study conducted of different anatomy department in different medical college of Bangladesh . the bellow medical college were selected for present study:

I. ARMED FORCES MEDICAL COLLEGE, DHAKA (AFMC)

II. ARMY MEDICAL COLLEGE, CUMILLA (AMCC)

III. EASTERN MEDICAL COLLEGE, CUMILLA (EMCC)

\section{Armed Forces Medical College (DHAKA)}

The Armed Forces Medical College (AFMC) is a military medical college in Dhaka cantonment, Dhaka, Bangladesh. It is run by the Military of Bangladesh and is under the Ministry of defense of Bangladesh. A Major General of Bangladesh Army's Medical corps is the commandant of the college. It has two types of student Medical cadets (AFMC cadets) and Army Medical corps cadets (AMC cadets). AFMC cadets can become civilian 
doctors after completing the MBBS course. But AMC cadets should join the Army Medical corps (AMC) of the Bangladesh. The academic activities of the Armed forces Medical college commenced through induction of 56 medical cadets on 20 June 1999 the college approved by (BMDC).

\section{Army Medical College, Cumilla (AMCC)}

Army Medical College Cumilla (AMCC) is a medical college in Cumilla district, Bangladesh. It was established in Cumilla cantonment by a sanction letter from the Ministry of Health .Army Medical college Cumilla is affiliated to Bangladesh University of professionals (BUP). At present 150 student are being inducted each year. Army Medical College Cumilla is affiliated to Bangladesh University of Professionals (BUP). At present 50 students are being inducted each year.

\section{Eastern Medical College, Cumilla (EMCC)}

Eastern Medical college is a private medical school in Bangladesh, established in 2005. The main campus is located beside the Dhaka-Chittagong highway atkabila in Burichang Upazila in the Cumilla District of Chittagong Division, it is affiliated with university of Chittagong.

The selected Anatomy department of different medical college areas was taken through selective questionnaire type sampling method. This method was followed for the subjective judgment of the author on the basis of importance of areas as well as the toxic effect of formalin intercity present on the study.

\section{Introduce at Anatomy department of AFMC, AMCC, EMCC}

At the Anatomy department in the Armed Forces medical college (AFMC). there are two dissecting rooms, one of them has been transformed into cadaver storage area where three modern stainless steel coffin and one refrigerators are located. Dissecting rooms are located in the top floor $\left(7^{\text {th }}\right)$ of the building. The rooms have sufficient windows located in the upper third of the walls which represent natural ventilation. Artificial ventilation comprised of few number of suction devices fixed on the wall as well as fans attached to the roof of the dissecting rooms. During anatomy sections body parts of the cadaver are sometimes kept drenched in $10 \%$ formalin solution in open containers or basin to be readily used for demonstration and teaching purpuses. Moreover model room, museum room, and taxidermy section are belong of Anatomy department in AFMC.

On the other hand the Anatomy department in Army medical college Cumilla (AMCC). There are one dissecting room and one cadaver storage room. Dissection and cadaver storage room are located in the basement of the building. The rooms have available windows located in the upper side of 
the wall which represents natural ventilation. Artificial ventilation comprised of the few number of suction devices fixed on the wall as well as fans attached to the roof of the dissecting rooms . Moreover some open container or basins/tray to be readily used for demonstration and teaching purpose.

Anatomy department of the Eastern medical college, there are one dissecting room which has been transformed into cadaver storage area where cadaver coffin are located. Dissecting rooms are located in the basement of the buildings. The rooms have few windows located in the upper position of the wall which represents natural ventilation. During Anatomy classes, body parts of the cadaver are sometime kept in open containers or basins to be used for demonstration.

\section{Participate number of medical students [AFMC, AMCC, EMCC]} Armed forces medical college:

The following members of the AFMC are participated present study:

Total students, n-125

Male - 35

Female-90

\section{Army Medical College, Cumilla:}

The bellow, students, are participated this study-

Total students, $\mathrm{n}=50$

Male $=09$

Female $=41$

\section{Eastern Medical College, Cumilla :}

The following members are assisted in present research study-

Total students, $\mathrm{n}-75$

Male-20

Female-55

\section{Procedure of Data collection:}

The present study was a cross sectional conducted in Department of Anatomy at Armed forces medical college Dhaka, Army Medical College Cumilla and Eastern Medical College Cumilla. The present study was carried out on $\mathrm{N}=125$ (AFMC) , N=75 (EMCC), N=50 (AMCC), healthy subject ( $1^{\text {st }}$ year MBBS students) between (19-21) years of age of three medical college who were routinely exposed to formalin during dissection class at least 5 days a week. Written informed consent was taken from all of them. Students having a history of cough, asthma, respiratory symptom, dermatological problems or allergy, were exclude from the study. There was no spillage of formalin in the lab. Condition of cadaver was good so there was 
no leak of fluid from the cadavers. There was good ventilation in the dissection hall with proper exhaust facilities.

\section{Research method:}

The medical students were subjected to a self administered predesigned questionnaire to collect information about symptoms of acute exposure to formalin treated cadavers such as Unfavorable scent, Tearing of eyes, Running nose with prickling sensibility, sore aphonia/throat, neuralgia/migraine, Inflammation of eyes, Scabies, Inconvenience inhale \& exhale, Qualm, giddiness, blister as well as annoyance on face and neck area. All these symptoms were arranged chronologically.

The collected data were coded and typed onto computer excel sheet, and data was further analyzed and interpreted for final appearance with the help of statistical techniques and analytic statistics including.

\section{Result and Discussion}

Armed forces Medical College (AFMC) Dhaka-Acute toxic effects of formalin during dissection classes on exposed AFMC students: [n=125]

Most of the students of AFMC complained symptom of acute exposure to formalin treated cadavers such as unfavorable scent (84.8\%), Running nose with prickling sensibility (61.6\%), tearing of eyes (84.8\%), Inflammation of eyes (63.2\%), Inconvenience inhale \& exhale (72.8\%), Qualm (80\%), In appetency (69.6\%), Giddiness (63.2\%), unusual nuisance(60\%), excessive tears/ lacrimation (87.2\%), unusual weariness (62.4\%), GIT disturbance $(80 \%)$ and Respiratory anxiety $(73.6 \%)$.

To a less extent students reported sore aphonia/ throat (49.6\%), Neuralgia/migraine (52\%), scabies (53.6\%), Lack of attention (44.8\%), unusual thirst $(44.8 \%)$. Itching in the eyes $(44.8 \%)$, disturbance in sight $(43.2 \%)$.

Syncope (fainting episode) (4.8\%), Blister (52\%), Annoyance on face and neck area (47.2\%)and Saccharum spontaneum/cough (50.4\%) (showed table 1).

In addition, AFMC medical students reported wearing laboratory aprons 87(69.6\%) and Hand gloves 71(56.8\%), however only 7(5.6\%), reported wearing eye goggles. 
Table 1: Comparative analysis of acute toxic effect of formalin during dissection classes on exposed AFMC, AMCC \& EMCC students

\begin{tabular}{|c|c|c|c|c|c|c|c|}
\hline \multirow{2}{*}{$\begin{array}{l}\mathrm{S} / \\
\mathrm{NO}\end{array}$} & \multirow{2}{*}{ Symptom } & \multicolumn{2}{|c|}{ AFMC, T.S-125 } & \multicolumn{2}{|c|}{ AMCC, T.S-50 } & \multicolumn{2}{|c|}{ EMCC, T.S-75 } \\
\hline & & No & $\%$ & No & $\%$ & No & $\%$ \\
\hline 1 & Unfavorable Scent & 106 & 84.8 & 43 & 86 & 57 & 76 \\
\hline 2 & Tearing of eyes & 106 & 84.8 & 45 & 90 & 54 & 72 \\
\hline 3 & $\begin{array}{l}\text { Running nose with prickling } \\
\text { sensibility }\end{array}$ & 77 & 61.6 & 41 & 82 & 49 & 65.33 \\
\hline 4 & Sore aphonia/Throat & 62 & 49.6 & 32 & 64 & 50 & 66.67 \\
\hline 5 & Neuralgia/ Migraine & 65 & 52 & 43 & 86 & 47 & 62.67 \\
\hline 6 & Inflammation of eyes & 79 & 63.2 & 42 & 84 & 50 & 66.67 \\
\hline 7 & Scabies & 67 & 53.6 & 39 & 78 & 47 & 62.67 \\
\hline 8 & $\begin{array}{l}\text { Inconvenience inhale \& } \\
\text { exhale }\end{array}$ & 91 & 72.8 & 43 & 86 & 50 & 66.67 \\
\hline 9 & Lack of attention & 56 & 44.8 & 39 & 78 & 46 & 61.33 \\
\hline 10 & Qualm & 100 & 80 & 42 & 84 & 45 & 60 \\
\hline 11 & In appetency & 87 & 69.6 & 28 & 56 & 53 & 70.67 \\
\hline 12 & Giddiness & 79 & 63.2 & 36 & 72 & 48 & 64 \\
\hline 13 & Unnatural nuisance & 75 & 60 & 31 & 62 & 40 & 53.33 \\
\hline 14 & Unusual thirst & 56 & 44.8 & 29 & 58 & 43 & 57.33 \\
\hline 15 & Itching in the eyes & 56 & 44.8 & 34 & 68 & 58 & 77.33 \\
\hline \multirow{2}{*}{$\begin{array}{l}\text { S/ } \\
\text { NO }\end{array}$} & \multirow{2}{*}{ Symptom } & \multicolumn{2}{|c|}{ AFMC, T.S-125 } & \multicolumn{2}{|c|}{ AMCC, T.S-50 } & \multicolumn{2}{|c|}{ EMCC, T.S-75 } \\
\hline & & No & $\%$ & No & $\%$ & No & $\%$ \\
\hline 16 & Extreme tears/Lacrimation & 109 & 87.2 & 43 & 86 & 37 & 49.33 \\
\hline 17 & Disturbance in sight & 54 & 43.2 & 28 & 56 & 35 & 46.67 \\
\hline 18 & Fainting episode (syncope) & 6 & 4.8 & 5 & 10 & 20 & 26.67 \\
\hline 19 & Unusual weariness & 78 & 62.4 & 28 & 56 & 53 & 70.67 \\
\hline 20 & GIT disturbance & 100 & 80 & 30 & 60 & 43 & 57.33 \\
\hline 21 & Respiratory anxiety & 92 & 73.6 & 29 & 58 & 49 & 65.33 \\
\hline 22 & Blister & 65 & 52 & 35 & 70 & 49 & 65.33 \\
\hline 23 & $\begin{array}{l}\text { Annoyance on face and neck } \\
\text { area }\end{array}$ & 59 & 47.2 & 18 & 36 & 41 & 54.67 \\
\hline 24 & $\begin{array}{l}\text { Saccharum } \\
\text { spontaneum/Cough }\end{array}$ & 63 & 50.4 & 19 & 38 & 33 & 44 \\
\hline
\end{tabular}

N.B: AFMC(Armed Forces Medical College) AMCC(Army Medical College, Cumilla)

EMCC (Eastern Medical College, Cumilla) T.S(Total Student ), GIT(Gastro Intestenial Tract)

Table 2: Comparative uses of protective materials of AFMC, AMCC \& EMCC students during dissection classes to protect formalin toxicity

\begin{tabular}{|c|c|c|c|c|c|c|c|}
\hline \multirow{2}{*}{$\begin{array}{l}\text { S/ } \\
\text { NO }\end{array}$} & \multirow{2}{*}{$\begin{array}{c}\text { Name of protective } \\
\text { materials }\end{array}$} & \multicolumn{2}{|c|}{ AFMC, T.S-125 } & \multicolumn{2}{|c|}{ AMCC, T.S-50 } & \multicolumn{2}{c|}{ EMCC, T.S-75 } \\
\cline { 3 - 8 } & No & $\%$ & No & $\%$ & No & $\%$ \\
\hline 1 & Eye goggles & 7 & 5.6 & 7 & 14 & 16 & 21.33 \\
\hline 2 & Hand gloves & 71 & 56.8 & 37 & 74 & 47 & 62.67 \\
\hline 3 & Laboratory Aprons & 87 & 69.6 & 46 & 92 & 55 & 73.33 \\
\hline
\end{tabular}

N.B: AFMC(Armed Forces Medical College) AMCC(Army Medical College, Cumilla) EMCC (Eastern Medical College, Cumilla) T.S(Total Student ), GIT(Gastro Intestenial Tract) 


\section{Army Medical College Cumilla [AMCC] Cumilla-Acute toxic effect of formalin during dissection classes on exposed AMCC students: [N-50]}

Table shows (table 1), percentage distribution of incidence of toxic effects of formalin of AMCC students which showed that $86 \%$ students had unfavorable scent followed by tearing of eyes and running nose with prickling sensibility in $90 \%$ and $82 \%$ respectively.

The other Symptoms reported were sore aphonia/ throat (64\%), neuralgia/migraine (86\%), Inflammation of eyes( $84 \%)$, scabies (78 $\%)$,Inconvenience inhale \&exhale( $86 \%)$, lack of attention( $78 \%)$, Qualm( $84 \%)$, Giddiness $(72 \%)$, Itching in the eyes (68\%) Extreme tears/ lacrimation $(86 \%)$, GIT disturbance (60\%), Unnatural nuisance $(62 \%)$, and blister $(70 \%)$.

To a lass extent students reported lnappetency(56\%), unusual thirst( $58 \%$ ), Disturbances in sight $(56 \%)$, syncope (fainting episode) (10\%), Unusual weariness ( $56 \%$ ), respiratory anxiety( $58 \%$ ), Annoyance on face and neck area $(36 \%)$ as well as Saccharum spontaneum/ Cough (38\%) respectively (table 2).

In addition AMCC medical student reported laboratory aprons 46 (92\%), and hand gloves 37 (74\%), however, only 7(14\%), reported wearing eye goggles.

Easter Medical College, CUMILLA (EMCC) Acute toxic effect of formalin during dissection classes on exposed EMCC students: $(\mathrm{N}=75)$

Most of the student of EMCC complained symptom of acute exposure to formalin-treated cadavers- such as- unfavorable scent $(76 \%)$, running nose with prickling sensibility $(65.33 \%)$, tearing of eyes $(72.00 \%)$, sore aphonia/ throat $(66.67 \%)$, Neuralgia/migraine $(62.67 \%)$, Inflammation of eyes $(66.67 \%)$, scabies (62.67\%), Inconvenience inhale \&exhale $(66.67 \%)$, Lack of attention (61.33\%), Qualm (60\%), In appetency(70.67\%), Giddiness (64\%), itching in the eyes $(77.33 \%)$, Unusual weariness $(70.67 \%)$ Reparatory anxiety $(65.33 \%)$ and Blister $(65.33 \%)$ (table 1$)$.

To a less extent student reported unnatural nuisance $(53.33 \%)$,Unusual thirst $(57.35 \%)$ extreme tears/ lacrimation (49.33\%), Disturbance in sight (46.67\%), syncope (fainting episode) (26.67\%), GIT disturbance $(57.33 \%)$, Annoyance on face and neck area (54.67\%) and Saccharum spontaneum/cough (44\%) (showed table 1).

Moreover, EMCC medical student reported wearing laboratory aprons/ coat $(73.33 \%)$, and hand gloves $(62.67 \%)$, however, only $(21.33 \%)$ reported wearing eye goggle/glass.

\section{Discussion}

In the present study we have quantified the different toxic effects of formalin in terms of incidence of Occurrence, chronological order and their 
severity in $\mathrm{N}=125,1^{\text {st }} \mathrm{MBBS}$ student of AFMC, and $\mathrm{N}=50,1^{\text {st }} \mathrm{MBBS}$ student of AMCC and $\mathrm{N}=75,1^{\text {st }}$ MBBS students of EMCC.

They have reported symptom such as- unfavorable scent $(84.8 \%$, $86 \%, 76 \%)$, tearing of eyes $(84.8 \%, 90 \%, 72 \%)$, running nose with prickling sensibility $(61.6 \%, 82 \%, 65.33 \%)$, Neuralgia/migraine $(52 \%, 86 \%, 62.67 \%)$, Inflammation of eyes $(63.2 \%, 84 \%, 66.67 \%)$, Inconvenience inhale \&exhale $(72.8 \%, 86 \%, 66.67 \%)$, Qualm $(80 \%, 84 \%, 60 \%)$.

In appetency $(69.6 \%, 56 \%, 70.67 \%)$, Giddiness $\quad(63.2 \%, 72 \%, 64 \%)$ extreme tears/ lacrimation $(87.2 \%, 86 \%, 49.33 \%)$, GIT Disturbance $(80 \%, 60 \%, 57.33 \%)$ of AFMC, AMCC and EMCC students respectively (table 1). In agreement with the results of the current research, in India (Dixit, et al; 2005) evaluated formaldehyde's toxic effect on medical students; his study revealed that the same most disturbing symptom were unpleasant Smell, itching of the eyes, watering of eyes, running nose with tingling sensation, GIT disturbance, excessive lacrimation and Nausea.

More ever, (Emue, et al; 2011) conducted a study on Nigerian medical students and found that the most common feelings and symptoms among studied medical students on first exposure include general discomfort $(81 \%)$, eye irritation /itching (48\%) and nasal irritation/itching 50\%.

In addition, (Abhijeet \&Yadav,2014) evaluated a research on Bundelkhand Medical College of Anatomy department and point out the most common symptoms among studied on first exposure such as- unpleasant small (30\%), excess lacrimation (24.67\%), running or congested nose $(20.67 \%)$, unusual tiredness or dizziness $(25.3 \%)$ and Sore throat $(17.33 \%)$.

It is noticed that those findings were approximately encountered our present study. (Elshaer\&Mahmoud,2017) Observed that symptoms due to formalin exposure are unpleasant smell (91.2\%), Dry or sore nose $(74.2 \%)$, itching in the eye $(81.4 \%)$, redness in the eyes $(72.4 \%)$, excessive lacrimation $(76.1 \%)$ and head ache $(53.6 \%)$, Which findings were most similar our present research findings. (Farah \&Praveen,2009) in their study have found that in the expose group $88 \%$, subjects suffer from eye irritation. $74 \%$ suffer from nose irritation, while $29 \%$ suffers from throat irritation and $21 \%$ from airway.

Moreover (Gousia Nisa,et al; 2016) mention that their study -water of eyes $(88.1 \%)$, Running nose with tingling sensation(30.7\%) and Jain SR et al.(2012)observed same symptom is - watering of eyes (87.2\%), tingling sensation in nose $(30.8 \%)$, which are encountered my current study report.

In the current research outstanding students of AFMC, AMCC \&EMCC were reported Skin symptoms such as- Scabies $(53.6 \%, 78 \%, 62.67 \%)$, Sore aphonia/ throat $(49.6 \%, 64 \%, 66.67 \%)$, and Annoyance on face and neck area $(47.2 \%, 36 \% \& 54.67 \%)$ respectively (table 1). Moreover, unusual thirst $(44.8 \%, 58 \%, 57.33 \%)$, Syncope (fainting 
episode) $(4.8 \%, 10 \%, 26.67 \%)$, and Saccharum spontaneum/Cough $(50.4 \%$, $38 \%, 44 \%$ ) faced of AFMC, AMCC and EMCC medical students (table 1).

Similarly in (Emue,et al; 2011) only $24 \%$ of studied medical students experienced skin irritation/ itching following their first exposure to formalin treated cadaver. Moreover (Yadav\& Abhijeet, 2014) only 12\%, (Jain SR,et al; 2012) (10.8\%) and (Gousia Nisa, et al; 2016) 10\% medical students faced skin problem eg; Itching, sore skin on hands, burning sensation their first exposure to formalin treated cadaver. This was explained by the fact that formalin has local skin irritant abilities, besides, medical students infrequently get in contact with formalin during cadaver dissection as they use hand gloves and laboratory coats at dissection.

In the current research, $69.6 \%$ students of AFMC reported wearing laboratory coat/aproans and $56.8 \%$ reported wearing hand gloves, where as $92 \%$ of AMCC students reported wearing laboratory coat and $74 \%$ students wearing hand gloves. On the other hand, $73.33 \%$ of EMCC students reports wearing laboratory coat and $62.67 \%$ students wearing hand gloves (table 2).

In agreement with the result of the current study, a large number of Nigerian and Egypt medical students reported using laboratory coat $(86 \%$, $78.1 \%)$ and hand gloves $(78 \%, 73.7 \%)$ respectively to reduce toxic effect of formalin.

Additionally in (Dixit,et al; 2005) in India, (69.2\%) of medical students were using gloves during cadaver dissection. On the other hand only $5.6 \%$ of AFMC students in the current study reported wearing eye goggles, where as $14 \%$ of AMCC students confessed wearing eye goggles. And only $21.33 \%$ of EMCC students find out wearing eye goggles, while $62 \%$ of Nigeria medical students and 55\% of Alexandria Faculty of medical (Egypt) reported using eye goggles during dissection.

\section{Conclusion and Recommendation}

Although, formalin has number of adverse effects and many medical professionals are unaware of them. Only Formaldehyde remains a popular embalming Chemical of preservative cadaver despite of its toxic effects because of its effectiveness low cost and tenacity result. Formaldehyde contains to be most potent agent used in embalming fluid as it is economical, excellent, preservative, and fixing solution. Hence, it should be used with proper monitoring and considering all its side effect.

So we need follow bellow precautionary method and recommendations to reduce the toxic effect of formalin.

Effective ventilation using active general or local exhaust ventilation is essential in reducing the concentration of formaldehyde. The ventilation system showed be checked under real working condition, e.g. with all the 
students in dissection room and at the beginning and end of the course and working hour.

Look for alternative embalming solution to reduce the amount of formaldehyde to hardly detectable levels, as in our department. However, one has to be aware of the health hazard of other chemicals in embalming solutions, Example Phenol this has a low vapor pressure but is absorbed dermally (Morimoto \& Wolff,1980),(Yager, et al; 1986).

The students and technicians should be informed about how to avoid unnecessary high concentration of formaldehyde and about wearing hand gloves, eye glass and Laboratory coat to reduce the likelihood of developing contact dermatitis.

Detailed discussions with all technicians and with student should take place before staring the dissection course, with the aim of achieving a more critical, balanced attitude towards the health hazard of formaldehyde in anatomy in relation to formaldehyde concentration in other environment, e.g; Cigarette smoke.

\section{Acknowledgements}

Author are very grateful and want to thank all the medical student who participated and readily filled the questionnaire. Moreover, they very much appreciate the cooperation and support of the staff members and workers at the AFMC, AMCC \& EMCC.

\section{References:}

1. Abhijeet Yadav; A study of the effect of the formalin on first year MBBS student; Department of Anatomy, Bundelkhand medical college, sagar(m.p) India . Sch. J. App.Med. Sci;(2014); 2(5b): pp1588-1590.

2. Bernstein RS, Styner LT, Elliott LJ, kimbrough R, Falk H, Blade L. Inhalation exposure to Formaldehyde: AN overview of its toxicology epidemiology, monitoring and control. Am Ind Hyg Assoc J, 45: pp778-85, (1984).

3. Bourne H G, S Seferman, wrinkle proofed clothing May liberate Toxic Quantities of Fomaldehyde. Med Surg Ind 28: 232, (1959).

4. Dixit D, AthaviaPD, PathakHM.Toxic effects of embalming fluid on medical students and professionals.JIAFM (2005);27(4):pp209-11.

5. Elshaer N S. M, Mahmoud M.A.E: Toxic effect of formalin treated cadaver on medical students, staff member, and worker in the Alexandria Faculty of Medicine, Egypt. Alexandria journal of medicine 53(2017) pp337-343. 
6. Emue BE, Ayanniyi AA, Nwegbu MM, Ibekwe TS. Acute effects of formalin treated cadaver on Nigerian medical students. Am j Trop Med pub Health. (2011);1:pp89-96.

7. Farah Khaliq and Praveen Tripathi: Acute effects of Formalin on pulmonary functions in gross anatomy laboratory: Indian $\mathrm{J}$ Physiol Pharmacol (2009); 53(1): pp93-96.

8. Gousia N, Bashir A.S, Shaheen S, Neelofar J, Sayma S, Showkat A: Acute toxic effect of formalin on First Year MBBS students during Dissection in Gross anatomy laboratory Srinagor, India. IOSR Journal of Dental and Medical Sciences (IOSR-JDMS). Volume 15, Issue 8Ver. X1 (August.2016), pp56-59.

9. Gross p.w Rinehart, R de Treville. The pulmonary Response to Toxic Gases. Am. Ind. Hyg. Assoc. J 28: 315,( 1967).

10. Jain SR, Nahar PS, Baig MM : Study of formalin toxicity in Ist MBBS students : International Journal Of Science And Research(IJSR) (2012); vol.1(3): pp 233-235.

11. Morimoto K, Wollf S. Increase of sister chromatid exchanges and perturbations of cell division kinetics in human lymphocytes by benzene metabolites. Cancer Res 40:pp 1189-93, (1980).

12. Morrill E. Formaldehyde Exposure from paper process solved by Air sampling and current studies. Air cond Heat Vent 53:94, (1961).

13. Stern AC. Air pollution. Academic press, New York 1: 484, (1968).

14. Walker JF. Formaldehyde Rinehold publishing corporation, New York 99, (1964).

15. Yager JW, Cohn KL, Spear RC, Fisher JM, Morse L. sister chromatid exchanges in Lymphocytes of anatomy students exposed to formaldehyde embalming solution. Mutat Res 174: pp135-39,(1986). 